\title{
PRÁTICA EDUCATIVA E EPISTEMOLOGIA DA EDUCAÇÃO: reflexões introdutórias
}

\author{
EDUCATIONAL PRACTICE AND EPISTEMOLOGY OF EDUCATION: introductory \\ reflections
}

\author{
Lohany Silva Bezerra dos Santos. ${ }^{1}$ \\ Samuel Nery Guimarães ${ }^{2}$ \\ Raimunda Alves Melo. ${ }^{3}$
}

\section{http://dx.doi.org/10.52641/cadcaj.v7i1.641}

\begin{abstract}
RESUMO: Este estudo é parte de uma pesquisa desenvolvida no âmbito do Programa de Bolsas de Iniciação Científica (PBIC/FAPEPI), cujo propósito é despertar vocação científica e incentivar novos talentos potenciais entre estudantes de graduação, estimulando pesquisadores vinculados à instituições de ensino e pesquisa do estado do Piauí a promoverem o acesso de estudantes de graduação aos processos de pesquisa científica, desenvolvimento tecnológico e inovação. A pesquisa em desenvolvimento, objetiva analisar a epistemologia da escola pública na contemporaneidade, com ênfase na caracterização da prática educativa de professores que trabalham nos anos finais do Ensino Fundamental. Com vistas o alcance desse propósito, realizouse uma análise do tema epistemologia e educação, situando do ponto de vista histórico, social, cultural e ideológico, os conceitos que embasam e relacionam essas duas categorias. Desenvolveuse a investigação por meio de pesquisa de abordagem qualitativa, por meio do método bibliográfico, à luz de leituras, como: Farias et al. (2011), Freire (2013; 2014), Libâneo (1994; 2006 [1985]), Luckesi (2001), Sacristán (1999), Saviani (1991; 2012 [1983]; 2013), Veiga (1992), entre outros. Os resultados apontam para a necessidade de ampliar os estudos sobre epistemologia da prática educativa escolar, a fim de evidenciar permanências e rupturas oriundas das diferentes perspectivas teóricas que fundamentam as práticas desenvolvidas, ampliando reflexões sobre a temática, bem como, elencando apontamentos para avançar na concretização de uma escola pública, laica e de qualidade para todos e todas.
\end{abstract}

Palavras-chave: Prática Educativa. Epistemologia da Educação. Escola Pública. Formação de Professores. Docência.

ABSTRACT: This study is part of a research developed under the Scientific Initiation Scholarship Program (PBIC/FAPEPI), whose purpose is to awaken scientific vocation and encourage new potential talents among undergraduate students, encouraging researchers linked to educational and research institutions in the state of Piauí to promote access for undergraduate students to scientific

\footnotetext{
${ }^{1}$ Graduanda do Curso de Licenciatura em Educação do Campo da Universidade Federal do Piauí (UFPI). E-mail: lohanysilva598@gmail.com

${ }^{2}$ Graduando do Curso de Licenciatura em Educação do Campo da Universidade Federal do Piauí (UFPI). E-mail: cajfr.2021128mage0016@aluno.ifpi.edu.br

${ }^{3}$ Doutora em Educação pela Universidade Federal do Piauí (UFPI). Professora do Curso de Licenciatura em Educação do Campo (LEdoC) da UFPI, Campus Ministro Petrônio Portella (CMPP), Teresina, Piauí, Brasil. E-mail: raimundinhamelo@yahoo.com.br
} 
research processes, technological development and innovation. The research in development aims to analyze the epistemology of the public school in contemporaneity, with emphasis on the characterization of the educational practice of teachers working in the final years of elementary school. In order to achieve this purpose, an analysis of the theme epistemology and education was performed, situating from the historical, social, cultural and ideological point of view the concepts that support and relate these two categories. The research was developed through qualitative research, through the bibliographic method, in the light of readings, such as: Farias et al. (2011), Freire (2013; 2014), Libâneo (1994; 2006 [1985]), Luckesi (2001), Sacristán (1999), Saviani (1991; 2012 [1983]; 2013), Veiga (1992), among others. The results point to the need to expand studies on epistemology of school educational practice, in order to evidence permanence and rupture stemming from the different theoretical perspectives that underlie the practices developed, expanding reflections on the theme, as well as, by displaying notes to advance in the realization of a public, secular and quality school for all and all.

Keywords: Educational Practice. Epistemology of Education. Public school. Teacher Training. Teaching.

\section{CONSIDERAÇÕES INICIAIS}

A educação é um processo de formação amplo e contínuo, desenvolvido em diferentes instituições sociais e influenciado por relações econômicas, políticas, culturais e ideológicas vividas pelos diferentes grupos sociais ao longo da história. Haydt (2006, p. 12) afirma que ao longo da história, a palavra educação tem sido utilizada com dois sentidos: social - "ação que as gerações adultas exercem sobre as gerações jovens, orientando sua conduta, por meio da transmissão do conjunto de conhecimentos, normas, valores, crenças, usos e costumes aceitos pelo grupo social”; e individual - [...] "desenvolvimento das aptidões e potencialidades de cada indivíduo, tendo em vista o aprimoramento de sua personalidade".

Diante dessas duas dimensões, a educação, no contexto de sua amplitude e complexidade, também é concebida como as diversas formas de sociabilidade humana, realizada nos diferentes momentos em que os sujeitos se encontram em relação uns com os outros, seja no âmbito familiar, no trabalho, no exercício da vida religiosa, no lazer, nas manifestações culturais, nas instituições educativas, seja em outras instituições e espaços de convivência humana. Veiga (1992) afirma que os processos educativos podem ser classificados em não-intencionais, realizados por meio das influências do contexto social e do meio ambiente sobre os indivíduos; ou intencionais, desenvolvidos através de ações em que há intenções conscientes, como é o caso da educação escolar e extraescolar.

Convém ressaltar que, a educação escolar é constituída de processos que visam aprendizagens formais e sistemáticas de interesse social, econômico, político, comunitário, entre outros. É na escola que a criança continua aprendendo a socializar, a trabalhar em grupo, a trocar 
experiências, a construir conhecimentos. Em síntese, as escolas surgiram como uma forma de organização social nascida da estratificação da sociedade, criada e regulamentada por um grupo específico para educar e ensinar, refletindo seus valores e a sua cultura (HAYDT, 2006). Contudo, Luckesi (2001, p. 30) afirma que a escola "dentro de uma sociedade não se manifesta como um fim em si mesmo, mas sim como um instrumento de manutenção ou transformação social”, paralelo aos valores e interesses vigentes.

O fato é que, ao longo da história da humanidade, a educação escolar esteve relacionada à formação de um certo tipo de ser humano, vinculada a determinada organização social e interesses divergentes e, por vezes, contraditórios. No contexto brasileiro, por exemplo, a educação introduzida pelos colonizadores portugueses com o auxílio irrestrito da Companhia de Jesus, predominou por todo o Período Colonial e, por influência cultural, também no Período Imperial e parte do Republicano, conforme estudos realizados por Saviani (2013).

Conforme Libâneo (2006), somente a partir das primeiras década do século XX que a educação brasileira foi invocada como fator de integração social e elevação da ordem política e econômica. Nesse cenário, diferentes concepções de educação passaram a orientar as práticas educativas desenvolvidas, com predominância daquelas que dialogam com os princípios liberais capitalistas, entre as quais, se destacam: a Pedagogia Tradicional, a Pedagogia Nova e a Pedagogia Tecnicista, todas elas fundamentadas nos ideais positivistas ${ }^{4}$.

A Pedagogia Tradicional, cuja concepção de educação concebe-a como redentora da humanidade, dispondo de um poder e de uma autonomia que independem da ordem social; a Pedagogia Nova, compreende a relevância do ato educativo para o afloramento das potencialidades da criança, pois entende que a libertação do homem é um processo que se inicia com a libertação da criança para desenvolver suas potencialidades inatas; a Pedagogia Tecnicista, alimentada pelo pragmatismo e pelo empirismo, atribui à educação, um viés utilitarista e imediatista da formação para o mercado de trabalho (LIBÂNEO, 2006).

No contexto atual, estudos desenvolvidos por Pimenta (2012), afirma que a sociedade contemporânea passa por rápidas transformações ocasionadas pelos avanços tecnológicos nos meios de comunicação, na economia, na sociedade, no mercado de trabalho, incidindo com bastante força na escola, aumentando os desafios de torná-la um espaço de aprendizagem e de formação para a cidadania. Reforça ainda que, a essas transformações, acrescenta-se a ampliação do acesso à escola e a consequente diversificação de culturas, cenário que vem se reconfigurando

\footnotetext{
${ }^{4}$ O Positivismo é uma corrente de pensamento filosófico, sociológico e político que surgiu em meados do século XIX na França, inspirada no ideal de progresso contínuo da humanidade. A principal ideia era a de que o conhecimento científico devia ser reconhecido como o único verdadeiro. Também postula a existência de uma marcha contínua e progressiva e que a humanidade tende a progredir constantemente.
} 
pelo surgimento de novos sujeitos escolares, de novas demandas e propostas educacionais, ampliando os desafios da escola em propiciar aos estudantes conhecimentos e o desenvolvimento de habilidades para que possam ir além dos saberes cotidianos, assumindo-os, ampliando-os e transformando-os em competências, de modo a se tornarem sujeitos ativos na mudança do seu contexto, na vivência e na convivência comunitária (PIMENTA, 2012).

Nesse cenário, ampliam-se as discussões e as exigências a respeito da necessidade de transformar as escolas e suas práticas culturais tradicionais e burocráticas que, por intermédio da retenção e da evasão, acentuam a exclusão social em espaços de inclusão social, que assegurem o desenvolvimento humano, social, cultural e tecnológico, oportunizando às crianças, jovens, adultos e idosos saberes e conhecimentos para que possam fazer frente às exigências do mundo contemporâneo.

Não há dúvidas de que a mudança dessa realidade exige esforço constante da comunidade escolar - diretores, coordenadores, professores, funcionários, famílias, estudantes, governantes e outros grupos organizados -, tendo em vista, as dificuldades que precisam ser enfrentadas no campo da qualidade das políticas educacionais em suas diferentes nuances. Essa questão tem, nas duas últimas décadas, mobilizado pesquisadores e gestores públicos na discussão de ações com vistas a garantir uma educação de qualidade, assegurada quando o aluno tem o seu direito de aprender em cada série cursada e quando estas aprendizagens são significativas do ponto de vista do educando, do educador e da sociedade em que se inserem.

Nesse sentido, a escola é, por referência, um dos principais espaços experimentados de modo sistemático pelos sujeitos, cuja proposta educativa é formada por uma intencionalidade política e pedagógica, pois, no seu compromisso em educar, é sua a responsabilidade de apropriação, (re) construção de conhecimentos pelos educandos, podendo contribuir de maneira significa para a vida dos sujeitos, quando assegura que estes ampliem os conhecimentos e as capacidades de conhecer, questionar e transformar a realidade da qual fazem parte.

Vivencia-se então, uma nova realidade, marcada pela necessidade de ampliação das discussões relativas aos desafios que estão postos, sobretudo, nas áreas consideradas mais urgentes, o que implica na necessidade de analisar as relações entre epistemologia e educação, com ênfase nas práticas educativas, aqui compreendidas, como aquelas que se constituem em uma ação mais extensa, pois, como afirma Freire (2013), na sua amplitude, possuem uma dimensão pedagógica e política, uma vez que a atividade de ensinar não se restringe apenas a sala de aula e a aprendizagem dos conhecimentos escolares, mas se desdobra pela ampliação de outros saberes e pela formação para a cidadania que se estende por toda a vida. 
A epistemologia é o estudo sobre a ciência tomada como sinônimo de conhecimento, ou seja, trata-se de uma teoria do conhecimento, que busca analisar os pressupostos e os fundamentos do conhecimento científico (DALAROSA, 2008). Dessa forma, investigar a epistemologia da escola pública na contemporaneidade, com ênfase na análise da prática educativa de professores significa produzir conhecimentos que caracterizem essa instituição, evidenciando as diferentes nuances que fundamentam a sua estrutura pedagógica e conceitual.

Como a educação está em movimento e, consequentemente, é processual, dinâmica, progressiva e pretende mudar os sujeitos, as práticas educativas devem estar munidas da consciência de que é tarefa urgente da educação, contribuir com a formação de sujeitos críticos, humanos e conscientes, razão pela qual, essa investigação poderá contribuir para melhores elucidações a respeito dessa questão.

Considerando essa perspectiva, o objetivo deste estudo é apresentar uma análise do tema epistemologia e educação, situando historicamente os conceitos que embasam e relacionam estas duas categorias e seus significados no contexto das práticas escolares, sobretudo.

\section{METODOLOGIA}

A pesquisa é essencial para a compreensão da realidade, a fim de responder problemas e desafios que permeiam a realidade humana, bem como, para a elaboração de novas formas e práticas de trabalho. No contexto educacional, seu objetivo é desconstruir e construir interpretações sobre as formas como os povos vivem e transmitem sua cultura, criam instituições escolares, desenvolvem as práticas educativas e elaboram as teorias que as orientam e/ou conduzem (MELO, 2014).

Com base nisso, desenvolveu-se pesquisa de abordagem qualitativa, por entender que melhor se adequa ao objeto e objetivos deste estudo. A respeito dessa abordagem, Richardson (2012, p. 80) afirma que "a metodologia qualitativa descreve a complexidade de determinado problema, analisa a interação de certas variáveis, compreende e classifica processos dinâmicos vividos por grupos sociais, contribuindo no processo de mudança de determinado grupo". Implica dizer que não possui um padrão único e ou fechado, porque aceita que a realidade é fluente e contraditória e os processos de investigação dependem do investigador, na sua concepção, seus valores, seus objetivos, assim, como a subjetividade dos pesquisados.

Os instrumentos de pesquisa são de suma importância para o alcance dos objetivos de uma investigação, pois é através deles que são produzidos os dados necessários para obter respostas a respeito do objeto investigado. Para atingir os objetivos, utilizou-se como dispositivos de 
produção de dados, a pesquisa bibliográfica, um método extremamente preciso e que fornece informações concretas, uma vez que, através da análise de outros estudos é possível extrair, resgatar, justificar informações, além de possibilitar o entendimento de objetos, cuja compreensão necessita de contextualização histórica (RICHARDSON, 2012).

\section{REFLEXÕES SOBRE PRÁTICA EDUCATIVA}

O que significa uma prática educativa? Para responder a essa indagação, recorre-se a Kolyniak Filho (1996, p. 111), segundo o qual: “prática é uma ação sobre o meio” [...] “toda a ação do homem sobre a natureza e sobre o outro homem”. Nesse sentido, sendo a prática uma ação não apenas do homem em relação à natureza, mas também, na sua relação com outros homens, ela pode revelar uma intenção, bem como, certo domínio de um conhecimento que leva o sujeito a agir de uma dada maneira, pois, como afirma Sacristán (1999, p. 69), "a prática educativa não é uma ação que deriva de um conhecimento prévio, mas sim uma atividade que gera cultura intelectual”.

As práticas educativas também são expressões concretas do ato de educar. Por essa razão, "tal como os hábitos de alimentação ou de higiene, geram uma cultura alicerçada em costumes, crenças, valores e atitudes" (SACRISTÁN, 1999, p. 69). Isso significa que nossos costumes, modos de agir, crenças, valores e atitudes podem revelar a influência da maneira de como somos e ou fomos educados, das práticas educativas que vivenciamos. É certo que uma prática educativa não ocorre apenas no ambiente formal, mas também em outros diversos espaços sociais, conforme explicitado na introdução deste trabalho.

Porém, indagações mais críticas sobre a epistemologia que fundamentam as práticas educativas encontram-se centralizadas nos espaços escolares, pois este é considerado privilegiado para a socialização de conhecimentos considerados como socialmente relevantes, não apenas aqueles que possuem cunho científico, mas também, que fazem parte do cotidiano dos sujeitos que os compõem, construindo aprendizagens e determinados comportamentos. Segundo Franco (2012), a prática educativa ocorre para a concretização de processos educacionais desenvolvidos dentro ou fora das escolas, cujos propósitos nem sempre estão claros para os sujeitos.

Isso porque, as práticas educativas revelam expressões concretas intencionais, uma vez que são fundamentadas em ideias que orientam a ação, muito embora, se reconheça que elas podem ser desenvolvidas não necessariamente da forma como foram idealizadas, pois a intervenção dos sujeitos da prática pode alterá-las. O fato é que, a constituição histórica das práticas educativas inclusas na educação escolar surge da necessidade de diferentes grupos sociais acessarem à escola 
e são intimamente interligadas às concepções de sociedade e de ser humano, concebidas pelo Estado e/ou grupos sociais (LEITE, 2002).

A prática educativa considera ainda, o conhecimento acumulado pela sociedade, como processo formativo que ocorre como necessária à atividade humana. Assim, deve-se considerar que trata-se de um fenômeno social e universal necessário à existência de todas as sociedades. Em âmbito escolar, a prática educativa se organiza intencionalmente, com o objetivo de atender a determinadas expectativas educacionais exigidas solicitadas pela sociedade ou mesmo, por um grupo dominante (MELO, 2018).

Enquanto fazer humano, a prática educativa não se realiza em um vazio, desenvolve-se e é condicionada em um contexto histórico, econômico, social e cultural determinado, sendo formada pelas ações, intenções, saberes, fazeres, atividades, interações e maneiras de agir sobre o meio, nos modos de se relacionar, nas formas de conhecimento das coisas, nas ações desenvolvidas pelos seres humanos para manutenção ou transformação do mundo. Libâneo (1994, p. 17) afirma que a educação, enquanto prática educativa, e no seu sentido amplo, "compreende os processos formativos que ocorrem no meio social, nos quais estão envolvidos de modo necessário e inevitável pelo simples fato de existirem socialmente".

Nessa perspectiva mais ampla de educação, Brandão (2013, p. 07) afirma que: "ninguém escapa da educação. Em casa, na rua, na igreja ou na escola, de um modo ou de muitos, todos nós envolvemos pedaços da vida com ela: para aprender, para ensinar, para aprender-e-ensinar". Assim, essa prática assume uma dimensão plural, espraiada por todos os âmbitos da vida humana, constituindo, portanto, um conjunto de "educações" na formação do sujeito.

A prática educativa consiste na concretização das condições que asseguram a realização do trabalho docente, que não se reduz ao aspecto pedagógico, uma vez que a escola cumpre funções que lhe são dadas pela sociedade, constituída por classes sociais com interesses antagônicos. Dessa forma, “a prática escolar assim, tem atrás de si condicionantes sociopolíticos que configuram diferentes concepções de homem e de sociedade e, consequentemente, diferentes pressupostos sobre o papel da escola, aprendizagem, relações professor-aluno", entre outros aspectos (LIBÂNEO, 2006, p. 19).

O processo educativo, onde quer que se realize, é consecutivamente contextualizado social e politicamente, pois há um condicionamento à sociedade que lhe faz exigências, determina objetivos e provê condições e meios de ação. Assim, a prática educativa e, especialmente, os objetivos, o conteúdo do ensino e o trabalho docente estão determinados por fins e exigências sociais, políticas e ideológicas (VEIGA, 1992), podendo expressar formas de poder, e, assim, atuar tanto a favor da manutenção e reprodução da realidade social, quanto a favor da transformação 
social, dependendo das finalidades dos processos educativos em que os sujeitos estão inseridos, mesmo que não tenham consciência do fato.

Desse modo, o que define a prática educativa e seus determinantes são as concepções daqueles que as praticam ou participam dos processos educativos sistemáticos ou não sistemáticos, carregados de expectativas determinadas por interesses sociais, ideológicos, políticos, econômicos e culturais de grupos específicos, razão pela qual, a consciência da epistemologia da prática educativa pretendida e desenvolvida é uma questão fundamental.

A prática educativa dos professores perpassa toda a tradição da educação, merecendo uma compreensão de sua estrutura histórica e atual, de modo a contribuir para a compreensão dos caminhos que caracterizam o exercício da docência na contemporaneidade. Libâneo (2006), afirma que a prática educativa dos professores é desenvolvida a partir das concepções que estes possuem sobre educação, ensino e aprendizagem, razão pela qual é relevante conhecer a epistemologia da prática educativa de professores.

Estudos desenvolvidos por Batista, Gouveia e Carmo (2016, p. 51) enfatizam o relevante papel da teoria no desenvolvimento e na compreensão da prática educativa desenvolvida, pois a teoria "está fundamentalmente relacionada à tradição como fluxo contínuo de referências e sentidos que nos constituem - no contexto prático do trabalho do docente". Assim, faz-se mister conhecer o significado da epistemologia da prática educativa dos professores, como condição fundamental para a compreensão dos avanços e dos desafios que estão postos na escola pública.

O fato é que as concepções docentes que norteiam as práticas educativas são elaboradas a partir das vivências e das experiência pessoais e de trabalho, dos processos de formação inicial e continuada, de modo que, a constituição dessas práticas são originárias de diferentes fontes de conhecimento, como ressalta Libâneo (2006): uma boa parte dos professores baseia sua prática em prescrições pedagógicas incorporadas por sua passagem pela escola ou transmitidas pelos colegas mais velhos; há professores capazes de perceber o sentido mais amplo de sua prática e de explicitar suas convicções, buscando a coerência entre a teoria e prática que desenvolvem; e alguns professores se apegam à última tendência da moda, sem maiores cuidados em refletir sobre as consequências que essa escolha trará para o fazer docente.

Assim sendo, compreender as concepções que norteiam a prática educativa dos professores é um processo complexo, que implica em conhecer com profundidade as suas experiências de vida, trabalho e formação; e ainda, conhecer a tradição educativa oriunda dessas diferentes perspectivas educativas e dos diversos entendimentos acerca das formas de educar as gerações. É através da análise epistemológica das práticas educativas que pode-se conhecer “em linhas gerais, tentativas de garantir o acesso ao conhecimento considerado instituído e, ao mesmo 
tempo, de governar atitudes, hábitos e sentimentos, isto é, de disciplinar os indivíduos para que eles vivam bem e adequadamente em sociedade" (BATISTA; GOUVEIA; CARMO, 2016, p. 50).

Freire (2013) afirma que os educadores devem ensinar com rigorosidade metódica, pois não há ensino sem pesquisa, aproximando o educando dos objetos cognoscíveis, com criatividade, investigação, curiosidade, humildade e persistência, ética e estética, levando à procura pelo esclarecimento, através de perguntas e indagações que fazem parte de uma prática que leva à autonomia do ser, ou seja, uma prática educativa crítica, consciente e emancipatória sobre as suas bases epistemológicas.

Segundo Vygotsky (1998), o bom ensino que se desenvolve por meio de práticas educativas é aquele que gera aprendizagem e colabora com o desenvolvimento de funções psíquicas superiores, ou seja, colabora com o desenvolvimento do pensamento, da linguagem, da memória, da atenção dirigida, da formação de conceitos, da consciência, entre muitas outras funções que tornam o homem qualitativamente diferente dos outros animais. Esse teórico reforça também, a importância do educador não perder de vista a formação humana, fundamentada em valores como afetividade, uma vez que:

A emoção não é uma ferramenta menos importante que o pensamento. A preocupação do professor não deve se limitar ao fato de que seus alunos pensem profundamente e assimilem a geografia, mas também que a sintam. [...] as reações emocionais devem constituir o fundamento do processo educativo. (VYGOTSKI, 1998, p. 121)

Neste sentido, implica diretamente na compreensão dos valores socioculturais vividos no cotidiano dos alunos e retratados em sala de aula, ajudando a construírem valores e sentimentos, como: empatia, respeito, solidariedade, justiça, entre outros, na preservação dos costumes e das tradições a serem mantidas no processo educativo. Isso é importante, pois, como diz Freire (2014), a educação deve se constituir numa prática a favor do exercício da liberdade e da construção de uma sociedade justa e humana.

Diante disso, finaliza-se este tópico, apresentando a carta de um sobrevivente de um campo de concentração, a fim de suscitar reflexões sobre a importância da consciência epistemológica da prática educativa escolar e a sua necessária relação com a formação de seres humanos, marcados pelo afeto e com compromisso para lutar a favor da vida, da transformação social e do amor ao próximo.

Sou sobrevivente de um campo de concentração. Meus olhos viram o que nenhuma pessoa devia presenciar. Câmaras de gás construídas por engenheiros ilustrados. Crianças envenenadas por médicos instruídos. Bebês mortos por enfermeiras treinadas. Mulheres e bebês mortos por ginasianos e universitários. 
Assim, desconfio da educação. Meu pedido é o seguinte: Ajudem os seus discípulos a serem humanos. Os seus esforços, nunca deverão produzir monstros cultos, psicopatas hábeis ou eichmanns instruídos. Ler e escrever, saber História e Aritmética só são importantes se servirem para tornar os nossos estudantes humanos. (BOLSANELLO; BOLSANELLO, 1986, p. 206).

Esse relato leva a reflexão sobre o papel dos educadores na formação de um perfil de ser humano, para, em um determinado modelo de sociedade, agir, interferir e ser influenciado sobre e pelo mesmo. É importante atentar para o fato de que a educação é um processo de formação que fornece os elementos necessários para a constituição desse perfil, e dependendo dos encaminhamentos utilizados, dos caminhos percorridos e das epistemologias que fundamentam as práticas, esse processo poderá resultar em "produtos” bem diferentes.

\section{REFLEXÕES SOBRE EPISTEMOLOGIA DA EDUCAÇÃO}

Partindo de uma concepção filosófica, o termo epistemologia, assume significados diferentes, uma vez que engloba reflexões e inquietações sobre as diferentes formas como o ser humano produz, utiliza e interpreta o conhecimento, estando ligado às diferentes pedagogias, sejam elas de cunho acrítico e liberal, sejas elas de caráter crítico e libertador.

Embora o ponto de partida para os estudos sobre epistemologia tenha sido dado por Platão, na Idade Antiga, que definiu três formas de conhecimento, a saber: doxa (conhecimento empírico opinativo, sensitivo), sofia (conhecimento acumulado, da sabedoria), episteme (conhecimento sistemático, reflexivo, analítico), foi com Kant que houve a separação entre filosofia e ciência, e esta passou a ser concebida como conhecimento vinculado à realidade material, física; ideia (DALAROSA, 2008). “Trata-se, pois, de uma reflexão epistemológica cuja preocupação fundamental é a de situar os problemas tais como eles se colocam ou se omitem, se resolvem ou desaparecem na prática efetiva" (JAPIASSU, 1992, p. 27).

No tocante à epistemologia da prática educativa, Carvalho (2007) afirma que não é possível efetuar análise ampla dos processos sociais e, sobretudo, educacionais, sem considerar as diferentes racionalidades projetadas pelas díspares teorias do campo da educação, uma vez que elas constituem um esforço para a obtenção de alternativas curriculares e metodológicas voltadas para a formação de professores em suas diferentes dimensões profissionais.

Batista, Gouveia e Carmo (2016) dizem que, no campo da educação, a análise epistemológica se refere ao que fica pressuposto nas práticas pedagógicas, ao que não é dito pelo professor em suas atividades, mas que está efetivamente atuante e patente na sua prática educativa. Desse modo, a epistemologia da prática educativa visa tornar latentes os conteúdos que orientam 
a incorporação, produção e utilização dos saberes ensinados e sua aplicação na prática educativa, indicando um "conjunto de saberes utilizados realmente pelos profissionais em seu espaço de trabalho cotidiano para desempenhar todas as suas tarefas" (TARDIF, 2014, p. 255) (Grifos do autor).

Sendo a epistemologia da prática educativa um campo de estudo do conjunto dos saberes utilizados pelos professores em seus respectivos espaços-tempos de atuação, para dar conta dos desafios que se colocam nas respectivas realidades, nas suas mais variadas ações e atividades, é fundamental que exista consciência docente sobre os fundamentos teóricos e metodológicos que orientam as práticas educativas desenvolvidas.

Isso é relevante, pois a constituição das práticas educativas desenvolvidas nas escolas são influenciadas por diferentes perspectivas pedagógicas desenvolvidas ao longo da história da educação brasileira. Batista, Gouveia e Carmo (2016, p. 50) afirmam que "desde o século XVII, com a Didática Magna de Comenius, com a descoberta da infância por Rousseau e com a institucionalização da educação por meio da invenção da escola, estamos no fluxo de uma longa tradição que também nos constitui”.

O modo como os professores realizam seu trabalho, selecionam e organizam o conteúdo das matérias, ou escolhem técnicas de ensino e fazem a avaliação da aprendizagem tem a ver com pressupostos teórico-metodológicos, explícita ou implicitamente, uma vez que, "uma escolha de pedagogia inevitavelmente comunica uma concepção do processo de aprendizagem e do aprendiz. A pedagogia jamais é isenta. Trata-se de um meio que carrega sua própria mensagem" (BRUNER, 2001, p. 67), ou seja, todo projeto de educação é construído a partir de concepções e teorias que sustentam as práticas. E nisso, segundo Freire e Shor (1986, p. 146), a educação “é, simultaneamente, uma determinada teoria do conhecimento posta em prática, um ato político e um ato estético". Por essa razão, torna-se relevante aprofundar os estudos que tratam sobre a epistemologia da escola pública na contemporaneidade, evidenciando as diferentes nuances que fundamentam as práticas desenvolvidas.

No tocante as perspectivas teóricas que fundamentam as práticas educativas, a partir de sua relação com os condicionantes sociopolíticos da escola, Libâneo (2006) classifica as tendências pedagógicas em liberais ${ }^{5}$ e progressistas. ${ }^{6}$. A Pedagogia Liberal é composta pelas tendências:

\footnotetext{
5 O termo liberal não tem o sentido de "avançado", "democrático", “aberto", como costuma ser usado. A doutrina liberal apareceu como justificativa do sistema capitalista que, ao defender a predominância da liberdade e dos interesses individuais na sociedade, estabeleceu uma forma de organização social baseada na propriedade privada dos meios de produção, também denominada saciedade de classes. A pedagogia liberal, portanto, é uma manifestação própria desse tipo de sociedade.

${ }^{6}$ O termo "progressista", emprestado de Snyders, é usado aqui para designar as tendências que, partindo de uma análise crítica das realidades sociais, sustentam implicitamente as finalidades sociopolíticas da educação. Evidentemente, a pedagogia progressista, não tem como institucionalizar-se numa sociedade capitalista; daí, ser ela, um instrumento de luta dos professores ao lado de outras práticas sociais.
} 
Tradicional, Renovada Progressivista, Renovada não-diretiva e Tecnicista; e a Pedagogia Progressista é formada pelas tendências: Libertadora, Libertária e a Crítico-social.

A Pedagogia Liberal sustenta a ideia de que a escola tem por função preparar os indivíduos para o desempenho de papéis sociais, de acordo com as aptidões individuais. Para isso, precisam aprender a adaptar-se aos valores e às normas vigentes na sociedade de classes, através do desenvolvimento da cultura individual. A Pedagogia Progressista surgiu em contraponto às proposições da Pedagogia Liberal, e defende a ideia de que é necessário trabalhar o conhecimento escolar em prol da formação de uma consciência política nos estudantes, uma vez que, a escola é vista como uma arma de luta contra as opressões, uma maneira de formar a classe trabalhadora social e politicamente (SAVIANI, 1991).

Ao longo da história, obteve-se formatos de ensino divergentes, criados a fim de superar as proposições da Pedagogia Tradicional e abrir espaços para novas perspectivas, como é o exemplo das tendencias pedagógicas liberais reformistas não críticas: renovada progressivista, não directiva e tecnicista, bem como, as mais atuais: liberais progressistas libertadora, libertária, críticosocial dos conteúdos ou histórico-critica.

Essas tendências, apesar de contribuírem para o desenvolvimento das práticas educativas em determinado período histórico e de influenciarem as atuais práticas desenvolvidas nas escolas, não conseguem atender a todas as necessidades educacionais, uma vez que os seus fundamentos epistemológicos estão ligados a determinados interesses de grupos sociais e políticos, predominantes em cada época. Contudo, não se pode desconsiderar a importância de analisar cada uma, entender o que elas propõem e como as mesmas podem contribuir para o atendimento das atuais necessidades das escolas e dos educandos.

No que tange a essas tendencias pedagógicas é importante frisar suas categorizações, conceitos e fundamentos. Quando se fala em fundamentos do fazer docente é de suma importância retratar autores e grandes pioneiros nesses estudos, como é o caso de Demerval Saviani, em: Escola e Democracia, obra de 19837; José Carlos Libâneo, no livro: Democratização da escola pública: a pedagogia crítico-social dos conteídos, obra de $1985^{\circ}$. Esses autores foram de fundamental importância na descrição e na organização teórica acerca das tendências pedagógicas e suas caracterizações basilares.

Por um lado, Saviani (2012) se utiliza da categoria (marginalidade) bem como, discriminação e desigualdades sociais para tentar explicar a educação ou como uma "válvula de escape", superação ou como atenuação ainda mais das violências. Com isso, ele aborda os três tipos

\footnotetext{
${ }^{7}$ Neste texto, citada a edição: Saviani (2012).

${ }^{8}$ Neste texto, citada a edição: Libâneo (2006).
} 
de teorias dentro das tendências pedagógicas: as não críticas, as crítico-reprodutivas e as críticas. E, por outro lado, Libâneo (2006) se preocupou em listar e diferenciar teorias liberais de progressistas, buscando explicar aspectos da educação na sociedade capitalista.

Mas, afinal qual o significado dessa termologia (tendências pedagógicas)? Como o próprio nome já diz, tendência é particularmente algo que se repete e se encontra com grande hegemonia em um determinado período, possuindo grandes adeptos. E pedagógicas por quê estão relacionadas com a área da educação, ou seja, essas tendências são guias, aportes para determinados comportamentos e ações no âmbito escolar. Vale ressaltar que, como bem cita Farias et al. (2011 p. 30):

[...] as tendências pedagógicas não se apresentam de forma estanque e sequenciada por uma cronologia linear. O desapontar de uma não significa, necessariamente, o silenciar de outras. A possibilidade da presença de várias orientações em um mesmo período histórico evidencia a contradição, o conflito e o confronto entre diferentes, e até antagônicos, projetos educacionais e sociais.

De acordo com esse pensamento, entende-se que não é necessário o fim de uma tendência para que outra seja adotada, pois, pode ser que haja o encontro de duas ou mais presentes na mesma escola, onde uma pode completar a outra ou refutá-la. Tudo vai depender do encaminhamento que a instituição dispõe para o uso de tais pedagogias, bem como, das definições e operacionalização do Projeto Político-Pedagógico (PPP) em contínua construção.

Voltando-se à tipologia dessas tendências pedagógicas brasileiras, iniciando-se pelas liberais, que não fazem jus ao nome, ao contrário do que o senso comum enfatiza, não têm relação com liberdade, pelo contrário, recebem esse nome, porquê têm como objetivo preparar os indivíduos para atuar na sociedade, moldando-os para atender aos interesses da burguesia. Dentre eles, estão presentes a teoria tradicional, renovada progressivista, renovadora não diretiva (escola nova) e tecnicista, conforme enfatizou-se na introdução deste estudo.

Estas se fundamentam no paradigma positivista, proposto por Auguste Comte, e asseguradas para tentar explicar os fenômenos de marginalidade, conforme afirma Saviani (2012). Convém ressaltar que, o positivismo é uma corrente filosófica, literária, econômica e política oriunda da França que tem como intuito primordial, o desenvolvimento social, através do conhecimento científico, compreendido como única forma de verdade e progresso.

A perspectiva positivista concebe a sociedade como uma grande máquina, um corpo vivo, em que cada uma de suas peças ou órgão - os indivíduos - tem um lugar e uma função que lhe é própria. Para os positivistas, este corpo funciona como um todo harmônico e perfeito, e, pela sua perfeição, não apresenta 
necessidade de mudança. Falar em mudança significa, pois, falar de risco, de morte, de comprometimento do que está posto. (FARIAS et al., 2011, p. 32)

É possível notar que essa ideia defendida pelos positivistas procura justificar os problemas sociais, colocando o indivíduo como o autor e único responsável pelos fatores sociais em falência, como forma de mascarar os impactos do capitalismo e favorecer a classe dominante. Com relação aos fenômenos de marginalidade, são descritos por Saviani (2012, p. 05) “como ignorância, ou seja, quem não possui conhecimento é marginalizado. A escola surge como antídoto à ignorância, logo um instrumento para equacionar o problema da marginalidade”.

Farias et al. (2011, p. 34-35) explicam que as tendências liberais se caracterizam "por não questionarem o modelo social que enseja desigualdades pela forma como organiza a produção da vida material; liberais, porque reforçam as teses do liberalismo econômico - teoria de sustentação do modo de produção capitalista". Assim, são denominadas também, como tendências pedagógicas reformistas, pelo fato de não abalarem os pilares que sustentam a sociedade capitalista e por colaborarem com a manutenção de seu status quo.

É valido ressaltar que, apesar de serem consideradas acrítica, elas ainda se encontram presentes em muitas escolas e fundamentam as proposições de muitas políticas públicas, uma vez que dialogam diretamente com interesses governamentais e políticos. A tendência liberal tradicional enfatiza o papel dos professores como centro do processo educativo, aquele que detém o saber, sendo os estudantes considerados como aprendizes passivos, que pouco ou nada sabem. A ênfase do ensino recai sobre a transmissão de padrões, normas e modelos dominantes; o ensino é mecânico e não valoriza o pensamento crítico dos educandos, mas apenas, a memorização e a transmissão de conteúdos, trabalhados de forma descontextualizada e separados da realidade dos estudantes.

Esse ensino tradicional que ainda predomina hoje nas escolas se constituiu após a Revolução Industrial e se implantou nos chamados sistemas nacionais de ensino, configurando amplas redes oficiais, criadas a partir de meados do século passado, no momento em que, consolidado o poder burguês, aciona-se a escola redentora da humanidade, universal, gratuita e obrigatória como um instrumento de consolidação da ordem democrática. (SAVIANI, 1991, p. 54)

Trata-se de uma perspectiva de educação predominante em muitas escolas, geralmente, implementada por meio de discursos disfarçados, mas com ações idênticas. No mais, entende-se que a mesma não atende às necessidades educativas dos estudantes, seja porque justificam as desigualdades sociais e educacionais, seja porque não proporciona resultados positivos em aprendizagem. Atualmente, existe consenso sobre a necessidade de um novo projeto educacional, 
inclusivo, significativo e contextualizado, capaz de atender e dialogar com as necessidades dos diferentes grupos sociais.

No rol das tendências liberais, encontra-se a renovada progressivista, também chamada escola nova, que teve início no século XX e como um de seus propositores, Dewey. Segundo essa visão, os estudantes possuem potencial para se desenvolverem sozinhos. É a chamada pedagogia do aprender a aprender, em que o professor apenas auxilia no desenvolvimento da aprendizagem e o meio ambiente atua como a necessária motivação dos alunos para seguir na direção do conhecimento. Essa tendência enfatiza a importância da constante conexão entre o ser humano e o mundo em que vive, a ação recíproca entre ambos, a interação entre professor e aprendiz, realizada em um ambiente intrinsecamente democrático (LIBÂNEO, 2006). A marginalidade na tendência renovada progressivista difere da tradicional, pois não é tratada mais como símbolo de ignorância, o marginalizado aqui é o rejeitado (SAVIANI, 2012).

Outra tendência liberal é a renovada não-diretiva, instituída por Carl Rogers, grande psicólogo que viu a necessidade de uma educação onde a formação de valores e de sentimentos fosse levada em consideração. Nessa perspectiva, o professor também é apenas auxiliar e deve manter boa relação com o aluno, a aula e a relação entre ambos deve ser prazerosa e servir de terapia. Analisando essas duas últimas teorias é possível notar uma relevância nesses pensamentos, porém, há lacunas e ideias incompletas, que não se desenvolvem na prática (FARIAS et al., 2011).

E, por último, nessa categoria liberal positivista, tem-se a tendência tecnicista, que se define por exigir a formação para uma mão de obra qualificada no mercado de trabalho da sociedade capitalista. Nessa, há a necessidade do controle, por um professor, que vai exigir eficiência e eficácia, ou seja, há um período de treinamento para que tudo ocorra perfeitamente, de acordo com o exigido pelo setor mercadológico.

Como o próprio nome já diz, exige técnica, haja vista que o considerado marginal já não é o considerado como ignorante (tendência tradicional), rejeitado (tendências progressivistas), mas, como diz o próprio Saviani (2012): é considerado resultado de ineficiência e da improdutividade, constituindo-se numa ameaça de instabilidade ao sistema capitalista. A ideia defendida é que o papel da educação é de contribuir para a intervenção dos problemas sociais.

No que tange às teorias Crítico-Reprodutivistas, Saviani (1991) categoriza-as em três tipos: Teoria do Sistema de Ensino como Violência Simbólica, Teoria da Escola como Aparelho Ideológico do Estado (AIE) e Teoria da Escola Dualista. Essas teorias se colocam em oposição ao positivismo.

Com relação às teorias progressistas (segundo modelo dentro das TPB), Farias et al. (2011) explicam que o papel da escola é contribuir com a elaboração e a consolidação de outro modelo 
social. Ou seja, que não mais sejam preparados para o individualismo e a competição, mas que predomine a igualdade e a paridade nas relações sociais, de modo que os indivíduos sejam formados para a transformar a sua realidade. Cabe a escola criar pontes entre o saber e as necessidades dos educandos, criando as condições necessárias para a transformação social. Nessa categoria estão inclusas as tendências: libertadora, libertária e histórico-crítica.

A pedagogia libertadora, conhecida também como Freiriana, por ter sido estabelecida por Paulo Freire (grande educador e filósofo) assume a responsabilidade de, através da educação, trazer conhecimento significativo, baseado no diálogo e no compartilhamento de informações e conhecimentos. Nesse percurso, professor e aluno se encontram em estado de constante aprendizado com o outro, através das vivências e da análise das realidades em que estão inseridos.

Um dos grandes ideais é fazer com que o docente sendo mediador, entenda as especificidades individuais e coletivas dos alunos, suas necessidades e suas potencialidades estudando a melhor forma de repassar os conteúdos propostos e sempre fazendo alusão ao contexto em que aquele aluno está inserido, entendendo o ato educativo como um ato político. Segundo Freire (2014), ao contrário da pedagogia tradicional liberal, o ensino deve acontecer de forma horizontalizada, dialógica, problematizadora, para despertar a consciência dos oprimidos, inquietá-los e levá-los à ação (libertação).

Por possuírem denominações semelhantes, a pedagogia libertária é muito confundida com a libertadora, porém, cabe frisar que nessa, há uma supervalorização da autogestão e da coletividade. Seus propositores defendem a ideia de democracia e se assemelha com a libertadora, por ignorar o autoritarismo e enfatizar a necessidade de organização entre os indivíduos.

E, por fim, a teoria crítico-social, que ao contrário das duas últimas, focaliza nos conteúdos como principal elemento que deve ser utilizado em sala de aula, terceirizando as vivências dos aluno e seus saberes prévios, assim como novas metodologias de ensino. Essa pedagogia defende que o conteúdo a ser repassado aos alunos deve ser instrumento utilizado para transformação da sociedade, ou seja, só deve ser ensinado o que servir de utilidade para o aluno mudar a sociedade, divergindo da libertadora e libertaria, porque nessa, não há crítica ao uso de autoridade e compreende o professor como centro do conhecimento. Nesse aspecto, aproxima-se das proposições da pedagogia tradicional (FARIAS et al., 2011).

A partir da análise desse conjunto de tendências e de ideias discutidas neste texto é possível observar que cada uma tenta, de maneira singular, defender suas teorias baseadas naquilo que visa para a sociedade, ora com ideias egocêntricas, ora com pensamentos plurais, porém, nenhuma se encontra completa, cada uma é extremista em uma só vertente, com olhar unilateral que acaba segregando e beneficiando uma só classe, uma só doutrina. 


\section{CONSIDERAÇÕES FINAIS}

As discussões aqui apresentadas, evidenciam, em síntese que, a prática educativa possui caráter multidimensional, composta por um conjunto de ações, atividades, interações, intenções, saberes e fazeres vivenciados pelos e entre os indivíduos, desenvolvida em diferentes contextos sociais em que as relações de tempos e espaços se intercruzam para a concretização de processos formativos desenvolvidos dentro ou fora das escolas.

A análise bibliográfica empreendida aponta que, numa perspectiva crítica de educação, reconhece-se que os processos educativos escolares não são neutros, eles expressam e determinam os interesses demandados pela sociedade, pressupõem concepções de mundo, de ser humano e de educação, razão pela qual é necessário compreender a epistemologia das práticas educativas escolares.

Desse modo, torna-se urgente a ampliação de estudos que tratam sobre prática educativa e epistemologia da educação, evidenciando permanências e rupturas oriundas das diferentes perspectivas teóricas que fundamentam as práticas escolares, contribuindo com a produção de conhecimentos científicos e reflexões teóricas sobre os avanços e os desafios, possibilitando aos leitores, pesquisadores e professores, da Educação Básica e do Ensino Superior, conhecimentos sobre essa temática, bem como, apontamentos para avançar na concretização de uma escola pública, laica e de qualidade para todos e todas.

\section{REFERÊNCIAS}

BATISTA, G. S.; GOUVEIA, R. A.; CARMO, R. O. S. A epistemologia da prática profissional docente: observações acerca de alguns desafios atuais. Ensino Em Re-Vista, Uberlândia (MG), v. 23, n. 1, p. 49-69, jan./jun., 2016. Disponível em:

http://www.seer.ufu.br/index.php/emrevista/article/view/35403. Acesso em: 22 nov. 2020.

BOLSANELLO, A.; BOLSANELLO, M. A. Conselho, análise do comportamento humano em Psicologia. Curitiba: Educacional Brasil, 1986.

BRANDÃO, C. R. O que é educação. São Paulo: Brasiliense, 2013.

BRUNER, J. A cultura da educação. Porto Alegre: Artmed, 2001.

CARVALHO, A. D. F. A racionalidade pedagógica da ação dos formadores de

professores: um estudo sobre a epistemologia da prática docente nos Cursos de Licenciatura da Universidade Federal do Piauí. 2007. 239 f. Tese (Doutorado em Educação) - Universidade Federal do Ceará, Fortaleza, 2007. 
DALAROSA, A. A. Epistemologia e educação: articulações conceituais. UERJ Humanit. Sci. App1. Soc. Sci. Linguist. Lett. Arts., Ponta Grossa, n. 16, v. 02, p. 343-350, dez., 2008.

Disponível em: https://revistas2.uepg.br/index.php/humanas/article/view/651. Acesso em: 22 nov. 2020.

FARIAS, I. M. S. de. et al. Didática e docência: aprendendo a profissão. 3. ed. Brasília: Líber Livro, 2011.

FRANCO, M. A. S. Práticas Pedagógicas nas múltiplas redes educativas. In: LIBÂNEO, J. C.; ALVES, N. (Orgs.). Temas de Pedagogia: diálogos entre didática e currículo. São Paulo: Cortez, 2012. p. 169-189.

FREIRE, P. Pedagogia da autonomia: saberes necessário à prática educativa de ensino. Rio de Janeiro: Paz e Terra, 2013.

FREIRE, P. Pedagogia do oprimido. Rio de Janeiro: Paz e Terra, 2014.

FREIRE, P.; SHOR, I. Medo e ousadia: o cotidiano do professor. 9. ed. Rio de Janeiro: Paz e Terra, 1986.

HAYDT, R. Curso de didática geral. 8. ed. São Paulo: Ática, 2006.

JAPIASSU, H. Introdução ao Pensamento Epistemológico. 7. ed. Rio de Janeiro: Francisco Alves, 1992.

KOLYNIAK FILHO, C. Teoria, prática e reflexão na formação do profissional em educação física. In: SIMPÓSIO PAULISTA DE EDUCAÇÃO FÍSICA, 5., 1996, São Paulo. Anais... São Paulo: [s.n.], 1996.

LEITE, S. C. Escola rural: urbanização e políticas educacionais. São Paulo: Cortez, 2002.

LIBÂNEO, J. C. Didática. São Paulo: Cortez, 1994.

LIBÂNEO, J. C. Democratização da escola pública: a pedagogia crítico-social dos conteúdos. 21. ed. São Paulo: Loyola, 2006. [1985].

LUCKESI, C. Filosofia da Educação. São Paulo: Cortez, 2001.

MELO, R. A. Licenciatura em Educação do Campo: formação de professores e prática educativa. 2018. 273 f. Tese (Doutorado em Educação) - Centro de Ciências da Educação. Universidade Federal do Piauí, Teresina, 2018.

MELO, R. A. Prática docente na escola do campo: diálogos sobre a articulação dos conhecimentos escolares aos saberes da cultura camponesa. 2014. 163 f. Dissertação (Mestrado em Educação). - Centro de Ciências da Educação. Universidade Federal do Piauí, Teresina, 2014.

PIMENTA, S. G. Apresentação da coleção. In: PIMENTA, S. G.; LIMA, M. S. L. Estágio e docência. São Paulo: Cortez, 2012. p. 11-20

RICHARDSON, R. J. Pesquisa social: métodos e técnicas. São Paulo: Atlas, 2012. 
SACRISTÁN, J. G. Consciência e acção sobre a prática como libertação profissional dos professores. In: NÓVOA, Antonio (Org.). Profissão professor. 2. ed. Porto: Porto, 1999. p. 6392.

SAVIANI, D. Pedagogia histórico-crítica: primeiras aproximações. 6. ed. Campinas: Autores Associados, 1991.

SAVIANI, D. Escola e democracia. 42. ed. Campinas: Autores Associados, 2012. [1983].

SAVIANI, D. História das ideias pedagógicas no Brasil. 4. ed. Campinas: Autores Associados, 2013.

TARDIF, M. Saberes docentes e formação profissional. 17. ed. Petrópolis: Vozes, 2014.

VEIGA, I. P. A. A prática pedagógica do professor de didática. Campinas: Papirus, 1992.

VYGOTSKY, L. S. A formação social da mente: o desenvolvimento dos processos psicológicos superiores. 6. ed. São Paulo: Martins Fontes, 1998. 